\title{
DIMENSIONAMENTO DE UM SISTEMA DE ABASTECIMENTO DE ÁGUA PARA ATENDER UM LOTEAMENTO NO MUNICÍPIO DE VERTENTES-PE
}

\author{
André Lima Castanha de Melo1 \\ Eduardo Cabral da Silva2 \\ Cláudio José de Freitas Vasconcelos3 \\ Wendell José Soares dos Santos4
}

\section{RESUMO}

O abastecimento de água é o item componente do sistema de saneamento básico e, portanto, elemento essencial para a boa qualidade de vida da população e manutenção da segurança hídrica para o desenvolvimento socioeconômico de uma região. O Agreste pernambucano sofre frequentemente com a escassez hídrica devido, principalmente, a irregularidade pluviométrica, intermitência dos regimes fluviais e as condições hidrogeológicas desfavoráveis ao acúmulo de águas subterrâneas em grande parte do seu território. O município de Vertentes está situado no Agreste de Pernambuco e enfrenta problemas de racionamento no seu abastecimento de água.O crescimento da necessidade de um sistema de abastecimento de água no município está diretamente ligado ao surgimento de vários loteamentos. Para atender essa necessidade é preciso apresentar a concessionária local um projeto com parâmetros técnicos para que possa ser executado um estudo de viabilidade técnica para disponibilizar água e atender a demanda. O objetivo deste trabalho é dimensionar um sistema de abastecimento de água que atenda de forma adequada a demanda de um trecho de um loteamento na cidade de Vertentes, considerando as perdas de cargas, a vazão de projeto, o diâmetro da tubulação em cada trecho em função da velocidade e vazão máxima, para que a pressão estática fica acima de 10m.c.a, determinar a potência do conjunto motor bomba, diâmetro da tubulação de recalque, assim como, propor medidas sustentáveis para racionalizar o abastecimento de água. $\mathrm{O}$ dimensionamento do trecho ramificado foi realizado com base na população residente no trecho do loteamento que já está comercializado. A população residente é de 380 habitantes, com

\footnotetext{
1 castanha76@gmail.com

2 eduardo.csilva@professores.unifavip.edu.br

3 claudio.vasconcelos@professores.unifavip.edu.br

${ }^{4}$ wendell.santos@professores.unifavip.edu.br
} 
consumo per capta de 2001/hab.dia. A vazão de projeto foi calculada em 1,61/s as tubulações de distribuição encontradas foram de diâmetros de $50 \mathrm{~mm}$ e $75 \mathrm{~mm}$. Para a estação elevatória, a tubulação de recalque foi de 50mme a potência da bomba foi de 1,5 CV. Dentre as alternativas sustentáveis para abastecimento de água, foi sugerido o uso de captação de águas pluviais e águas cinzas, para serem utilizadas alternadamente com o uso convencional de abastecimento.

Palavras-chave: Segurança hídrica. Sustentabilidade. Agreste pernambucano. 


\section{INTRODUÇÃO}

A água é algo essencial para um sistema de abastecimento de água de qualquer região. É um recurso natural abundante e essencial para existência de vida na terra. De toda água disponível no planeta $97,5 \%$ é de água salgada que não é adequada ao consumo direto e apenas $2,5 \%$ é de água doce. Parte desta água doce é de difícil acesso e encontrada nas geleiras e outra parte fica acondicionada em aquíferos, sendo que apenas $1 \%$ está em rios e lagos (ANA,2019)

Para atender os usos múltiplos da água é necessário um sistema de abastecimento de água - SAA que supra a demanda em termos quantitativos, que obedeça às exigências normativas e tenha políticas de sustentabilidade ambiental. O sistema de abastecimento pode ser caracterizado pela utilização de equipamentos e serviços destinados ao abastecimento de água, para fins domésticos, serviços públicos, abastecimentos industriais, dessedentação de animais e irrigação (HELLER e PÁDUA,2010)

Os SAA fomentam a prevenção e o controle de doenças, como também ajudam a implantar hábitos higiênicos na população. Além do aspecto econômico, onde se aumentando a vida média com a redução da mortalidade, e com a redução do tempo em hospitais causado por doenças, a produtividade do ser humano aumenta. Consegue-se com um sistema de abastecimento facilidades de instalação de indústrias e o desenvolvimento de regiões, ainda conseguimos facilidade no combate aos incêndios.

Com relação aos elementos de um sistema de abastecimento de água podemos considerar o manancial, a captação, a adução, o tratamento, a reservação e a rede de distribuição e ligações prediais, que bem dimensionado podemos atender as expectativas de entregar uma água potável com qualidade dentro dos padrões estabelecidos.

No município de Vertentes, Agreste setentrional de Pernambuco, devido à crise hídrica da região, a Companhia Pernambucana de Saneamento (COMPESA), faz o abastecimento de água na forma de rodízio, sendo dois dias com água e 28 sem, atendendo a apenas 50\% dos bairros.

Ainda segundo a COMPESA, em abril de 2018 a barragem de Jucazinho, a principal fonte de abastecimento desta região, encontrava-se com $2,58 \%$ da sua capacidade e em janeiro de 2019, atingiu $3,2 \%$ da sua capacidade total, mas trabalhando de forma bastante reduzida 
devido as chuvas na região estarem abaixo da média.

Segundo a APAC- Agencia Pernambucana de águas e clima, em seu boletim de reservatórios, os primeiros sinais de recuperação da barragem de Jucazinho foram dados no mês de março de 2020. Atualmente, o reservatório está com $30,23 \%$ da sua capacidade total de 204 milhões de metros cúbicos.

Com a falta de abastecimento contínuo, a cidade possui alguns bairros que não são contemplados com um sistema de abastecimento de água, sendo necessária a utilização de caminhões-pipa.

Com a implantação de um sistema de abastecimento ele irá contribuir para

\section{MÉTODOLOGIA}

\section{Caracterização área de estudo}

Acidade de Vertentes, segundo os dados disponibilizados pelo Instituto Brasileiro Geografia e Estatística IBGE (2019), tem uma população estimada de 21.731 habitantes, fica localizada no agreste setentrional de Pernambuco (Figura 9). Sua área de unidade territorial é de aproximadamente $196,325 \quad \mathrm{~km}^{2}$.Possui vários loteamentos que não são contemplados com um SAA e o loteamento definido para área de estudo será o Loteamento João Santo. Ainda segundo o IBGE (2019), a cidade de Vertentes, melhorar a qualidade de vida dos moradores, além contribuir diretamente para prevenção e redução de doenças que possam estar ligadas diretamente aos hábitos higiênicos.

O presente trabalho tem como objetivo desenvolver um sistema de abastecimento de água como uma alternativa para atender a demanda de um loteamento nas condições que a Companhia Pernambucana de Saneamento (COMPESA)atende hoje.

apresenta $39 \%$ de domicílios com esgotamento sanitário adequado, $37.3 \%$ de domicílios urbanos em vias públicas com arborização e $14.3 \%$ de domicílios urbanos em vias públicas com urbanização adequada.

A cidade de Vertentes, possui um clima semiárido e de acordo com APAC (Agencia Pernambucana de Águas e Clima), através do monitoramento pluviométrico (Anexo4), a média anual de precipitação pluviométrica no município de Vertentes, é de $35,96 \mathrm{~mm}$, sendo que considerando os meses de abril, Maio e Junho essa média fica acima dos 60mm.

O Loteamento de área de estudo, está localizado na zona urbana da cidade de 
Vertentes (Figura 10), nas margens da PE130 e PE-90, abrangendo uma área de 104.414,00 m2, ou seja, 10.4414 hectares, com o uso dos lotes residencial, com quatrocentos e trinta e seis (436) lotes, (20) vinte quadras e (17) dezessete ruas projetadas.

Figura 9 - Mapa de Localização do Município de Vertentes-PE, no Agreste de Pernambuco.

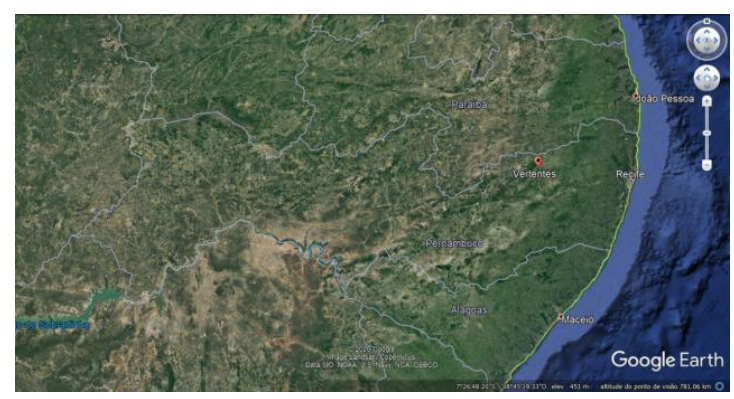

Fonte: GOOGLE, 2020

Figura 10 - Mapa localização área de estudo

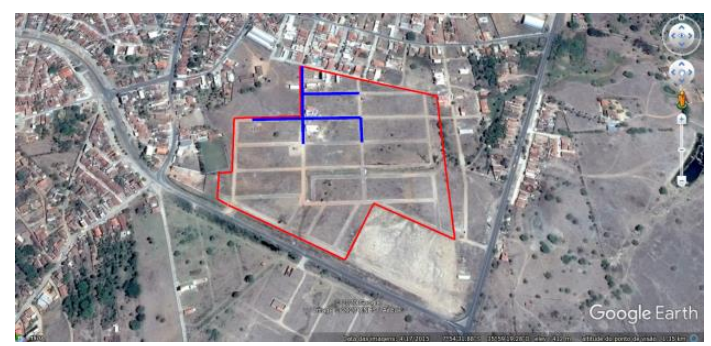

Fonte: GOOGLE, 2020.

Parâmetros genéricos e critérios básicos de projeção

Foram utilizados os critérios e parâmetros contidos nas normas da Associação Brasileira de Normas Técnicas (ABNT), voltados para a elaboração de sistemas de abastecimento de água, as quais descrevem o processo de desenvolvimento deste tipo de projeto, desde sua captação até a distribuição.
- NBR 12211/92 (Estudos de concepção de sistemas públicos de abastecimento de água);

- NBR 12212/92 (Projeto de poço para captação de água subterrânea);

- $\quad$ NBR 12215/91 (Projeto de Adutora de Água para Abastecimento Público);

- $\quad$ NBR 12218/94 (Projeto de rede de distribuição de água para abastecimento público);

Segundo a NBR-12218/1994, os parâmetros a serem observados e garantidos no momento da execução do projeto de uma rede de abastecimento de água são:

- Diâmetro mínimo para tubulação $50 \mathrm{~mm}$

- Pressão Dinâmica mínima - 10 m.c.a.

- $\quad$ Pressão Estática Máxima - 50 m.c.a.

- $\quad$ Material da Tubulação - PVC

- Rugosidade das paredes da tubulação (C) - 140

\section{Cálculo de estimativa populacional}

Para efetuar o cálculo da estimativa populacional considerou-se um levantamento quantitativo e informações colhidas in loco. A área de estudo possui 95 lotes e a média de habitantes é de 04 habitantes/lote chegando a uma população prevista de 380 habitantes. 


\section{Vazão do projeto}

Para determinar a vazão de projeto utilizado no pré-dimensionamento foi considerado o coeficiente do dia de maior consumo $\left(K_{1}=1,2\right)$, o coeficiente da hora de maior consumo $\left(\mathrm{K}_{2}=1,5\right)$ e o consumo per capta padrão médio (200 1/hab.dia). O cálculo da vazão máxima (Eq. 1) expressa em litros será dada pela formula:

$Q=\frac{n \cdot k 1 \cdot k 2 \cdot p}{86400}$

Onde:

$\mathrm{Q}=\operatorname{vazão}(1 / \mathrm{s})$,

$\mathrm{k}_{1}$ = coeficiente do dia de maior consumo;

$\mathrm{k}_{2}=$ coeficiente da hora de maior consumo;

$\mathrm{p}=$ população atendida (hab);

$\mathrm{n}=$ consumo diário per capita (1/hab.dia);

\section{Perdas de Carga}

As perdas de carga ao longo da tubulação têm seus valores encontrados através da fórmula de Hanz-Wiliams (Eq.2).

$$
\mathrm{J}=10,643 \frac{Q^{1,85}}{C^{1,85} D^{4,87}} L
$$

Onde:

$\mathrm{Q}=\operatorname{vazão}\left(\mathrm{m}^{3} / \mathrm{s}\right)$;

$\mathrm{D}=$ diâmetro $(\mathrm{m})$;

$\mathrm{C}=$ coeficiente adimensional referente à rugosidade do material da tubulação;

$\mathrm{L}=$ comprimento do trecho $(\mathrm{m})$;
$\mathrm{J}=$ perda de carga por trecho $(\mathrm{m} / \mathrm{m})$.

\section{Diâmetro da tubulação (D)}

O diâmetro da tubulação dos trechos será determinado em função da velocidade máxima de cada trecho encontrada através da equação da continuidade (Eq. 3).

$V=\frac{4 x Q}{\pi D^{2}}$

Onde:

$\mathrm{Q}=\operatorname{vazão}(\mathrm{m} 3 / \mathrm{s})$;

$\mathrm{D}=$ diâmetro $(\mathrm{m})$;

\section{Vazão unitária distribuída}

Relação entre a vazão total de distribuição pelo comprimento total da rede, calculada pela Eq. 4

$q_{m}=\frac{Q t}{L t}$

Onde:

$\mathrm{q}_{\mathrm{m}}=$ vazão unitária (1/s.m);

$\mathrm{Q}_{\mathrm{t}}=$ Vazão do projeto $(1 / \mathrm{s})$

$\mathrm{L}=$ comprimento total da rede $(\mathrm{m})$;

\section{Cálculo das vazões de distribuição}

\section{Vazão de distribuição em marcha}

O valor da distribuição em marcha, vazão de transporte em cada trecho da tubulação, será calculado pela Eq. 5 


$$
\mathrm{Qm}=\mathrm{qm} . \mathrm{L}
$$

Onde:

$\mathrm{Q}_{\mathrm{m}}=$ Vazão em marcha(l/s);

$\mathrm{q}_{\mathrm{m}}=$ Vazão unitária $(1 / \mathrm{s})$

$\mathrm{L}=$ Comprimento do trecho $(\mathrm{m})$;

\section{Vazão montante e jusante}

Com a determinação das vazões de montante e jusante de cada trecho, calculadas considerando as extremidades da rede como nós secos e utiliza-se estes valores para cálculo da vazão fíctícia (Eq.6), que será necessária para dimensionarmos o diâmetro da tubulação da rede.

$\mathrm{Qf}=\frac{\mathrm{Qj}+\mathrm{Qm}}{2}$

Onde:

$\mathrm{Q}_{\mathrm{f}}=$ Vazão Fictícia $(1 / \mathrm{s})$;

$\mathrm{Q}_{\mathrm{j}}=$ Vazão trecho a Jusante $(1 / \mathrm{s})$

$\mathrm{Q}_{\mathrm{m}}=$ Vazão trecho a montante(1/s);

\section{Pressões finais, estática e reservatório}

Para a definição dos valores finais de pressão em cada trecho e cota do reservatório foi levado em consideração as orientações da NBR 12218/94, baseando todos os dados técnicos e critérios das velocidades e perdas de carga entre cada trecho através da fórmula de HazenWillians, para tubos de PVC (140).

\section{Dimensionamento do conjunto motor- bomba}

Para cálculo da potência do conjunto motor-bomba (Eq. 7) foi considerado a altura manométrica e a vazão de recalque calculada para atender a demanda da rede.

$\mathrm{P}=\frac{\gamma \cdot \mathrm{Q} \cdot \mathrm{Hm}}{75 \cdot \mathrm{n}}$

Onde:

$\mathrm{P}=$ Potencia $(\mathrm{CV})$

$\gamma=$ Peso específico da água $\left(\mathrm{kgf} / \mathrm{m}^{3}\right)$

$\mathrm{Q}=$ Vazão de recalque $\left(\mathrm{m}^{3} / \mathrm{s}\right)$

$\mathrm{Hm}=$ Altura manométrica $(\mathrm{m})$

$\mathrm{n}=$ rendimento do conjunto motor bomba

A vazão de recalque foi calculada por meio da Eq. 8

$Q=\frac{V}{T}$

Onde:

$\mathrm{Q}=$ Vazão $\left(\mathrm{m}^{3} / \mathrm{h}\right)$;

$\mathrm{V}=\mathrm{V}$ olume $\left(\mathrm{m}^{3}\right)$

$\mathrm{T}=$ Tempo $(\mathrm{h}) ;$

Para dimensionamento do conjunto motor bomba deve ser considerada a altura manométrica que é definida pela soma da altura geométrica e as perdas de carga ao longo da tubulação de recalque, não foi considerada a perda localizada.

A Altura geométrica foi considerada a cota do reservatório de $10 \mathrm{~m}$ e a perda de 
carga ao longo da tubulação foi calculada pela Equação 2.

$\mathrm{O}$ valor da altura manométrica foi calculado pela soma da altura geométrica e a perda de carga ao longo da tubulação de recalque (Eq. 9).

$\mathrm{Hm}=\mathrm{Hg}+\mathrm{J}$

Para determinar a bomba é necessário consultar o manual de curvas características das bombas (Anexo 1) do fabricante KSB e escolher o modelo de acordo com a vazão e altura manométrica.

O diâmetro da tubulação de recalque (Dr) é obtido pela equação 10 e o de sucção (Ds) será considerado um valor imediatamente superior ao valor comercial adotado para o diâmetro da tubulação de recalque.

\section{RESULTADOS E DISCUSSÕES}

\section{Dados de concepção do SAA}

O critério de vazão definida no projeto para os lotes habitados, foi o de contribuição localizada em cada trecho, considerando uma população definida por 95 lotes e quatro moradores por unidade, gerando um total de 380 habitantes com um consumo diário per capta de 2001/hab.dia.

\section{Oferta e demanda de água}

$$
D_{r}=1,3 \sqrt[4]{\frac{T}{24}} \sqrt{Q}
$$

Onde:

$\mathrm{D}_{\mathrm{r}}=$ Diâmetro tubulação de recalque

$\mathrm{Q}=\operatorname{Vazão}\left(\mathrm{m}^{3} / \mathrm{s}\right)$;

$\mathrm{T}=$ Tempo $(\mathrm{h})$;

Para definir os diâmetros é necessário calcular a velocidade econômica para comprovar que a velocidade econômica (Eq.11) fique entre 0,5 e 4,0 m/s. $v=\frac{4 x Q}{\pi x D^{2} r}$

Onde:

$\mathrm{v}=$ velocidade econômica

$\mathrm{Q}=\operatorname{Vazão}\left(\mathrm{m}^{3} / \mathrm{s}\right)$

$\mathrm{D}=$ Diâmetro tubulação (m);

O loteamento, área de estudo deste trabalho, que está localizada na cidade de Vertentes,conforme monitoramento hidrológico da APAC, sofre com a crise hídrica e também com a irregularidade na precipitação pluviométrica ao longo dos anos. Em janeiro de 2019 o abastecimento na cidade era feito com um rodízio de um dia com água e 29 dias sem água, pois a barragem de Jucazinho, principal reservatório na região, trabalhava com apenas $3,17 \%$ da capacidade e somente os setores com um SAA poderiam ser contemplados, caso contrário, a solução seria recorrer ao caminhão-pipa. A 
barragem de Jucazinho, segundo o monitoramento de reservatórios da APAC, acumula no início de junho de 2020, 33,2\% da sua capacidade, valor que pode garantir pelo menos um ano de abastecimento na cidade em sistema de rodízio, chegando água para setores em até duas vezes ao mês.

\section{Elaboração do projeto de SAA}

Com a definição dos parâmetros técnicos, foi realizado os cálculos iniciais do dimensionamento e o traçado da rede.

Utilizou-se os coeficientes $\mathrm{k}_{1}=1,2$, $\mathrm{k}_{2}=1,5$, a população de projeto e o consumo per capto. $\mathrm{O}$ material da tubulação escolhido foi o de PVC, com coeficiente de rugosidade (C) de 140. A vazão obtida foi de $1,5831 / \mathrm{s}$.

\section{Traçado da rede}

Com o levantamento topográfico (Figura 11) e a definição do trajeto da rede (Figura 12), foram verificadas distancias nos trechos e as cotas dos nós. Foi verificado cotas máximas em $\mathrm{N} 1$ e $\mathrm{N} 8$ de 402m e cota mínima em N7 de 392m, de forma que a topografia do terreno tenha contribuição para o trajeto escolhido e a possibilidade de um dimensionamento adequado.

Figura 11 - Levantamento topográfico do loteamento no município de Vertentes-PE.
As linhas azuis mostram o traçado da rede de abastecimento de água.

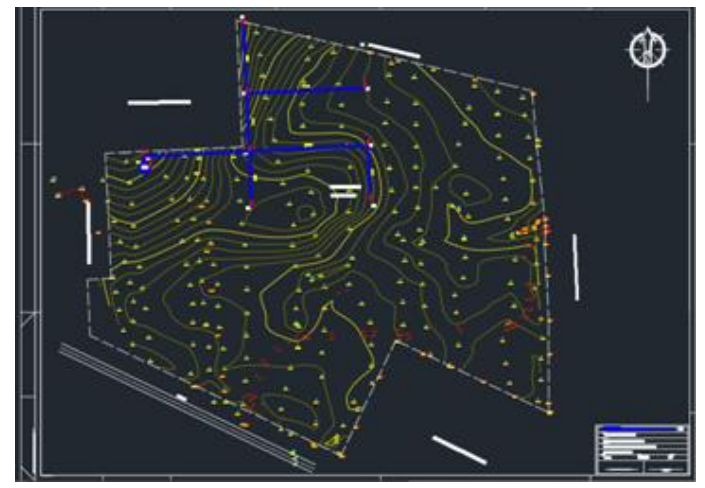

Fonte: Autor

O traçado da rede levou em consideração atender a população dos lotes habitados e a declividade do terreno. Com estes dados disponíveis foi possível obter o resultado da vazão unitária $\mathrm{q}_{\mathrm{m}}=0,003 \mathrm{l} / \mathrm{s}$.

Figura 12- Rede ramificada de abastecimento de água

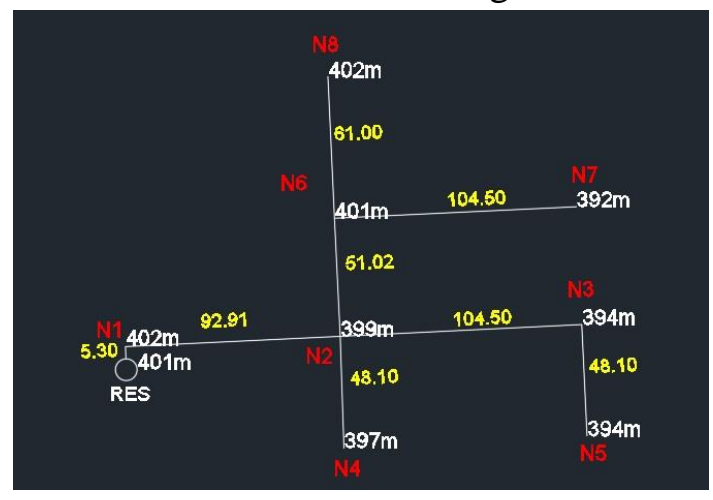

Fonte: Autor

\section{Cotas de montante e jusante}

Considerando o traçado da rede e verificando cada trecho, conseguiu-se uma cota máxima em N1 de 402,0 m no trecho 7(trajeto entre N1 e N2) e no trajeto N6 e N8 também temos uma cota máxima de 402,0 m, porém N8 é considerado um nó seco. O traçado da tubulação principal 
engloba o trecho o trecho 7 com extensão de 92,9m e o trecho 4 com extensão de 104,5m (trajeto N2 e N3), sendo a considerada as tubulações secundarias os trechos 1,2,3,5,6. Analisando cada trecho obtiveram-se os valores das cotas de montante e jusante conforme Tabela 2.

Tabela 2 - Informações dos trechos do loteamento objeto de estudo - extensão dos trechos e contas de montante e jusante.

$$
\text { Cota (m) }
$$

\section{Trechos Extensão Montante Jusante}

\begin{tabular}{cccc}
\hline 1 & 61 & 402,00 & 401,00 \\
2 & 104,5 & 392,00 & 401,00 \\
3 & 51,02 & 399,00 & 401,00 \\
4 & 104,5 & 402,00 & 394,00 \\
5 & 48,1 & 394,00 & 394,00 \\
6 & 48,1 & 399,00 & 397,00 \\
7 & 92,91 & 402,00 & 399,00 \\
8 & 5,3 & 401,00 & 402,00 \\
\hline
\end{tabular}

Fonte: Autor.

\section{Vazão em marcha}

Foi encontrada a vazão de transporte (vazão em marcha) de cada trecho (Tabela 3) utilizando os parâmetros do traçado da rede definidos no início do projeto, ou seja, utilizou-se a vazão de unitária $(\mathrm{qm})=0,003$ 1/s, multiplicando pelo comprimento (extensão) de cada trecho, considerado desta forma, os resultados $\mathrm{Q}_{\text {trecho }}(\mathrm{L} / \mathrm{s})$. No trecho 7 , onde se tem a cota máxima a montante, foi encontrado o resultado de 0,291/s para vazão em marcha, já nos trechos 2 e 4 foram encontrados os valores máximos das vazões em marchas de $0,321 / \mathrm{s}$, onde temos as maiores extensões da rede.

Tabela 3 - Informações de valores em marcha por trecho e extensão

\begin{tabular}{ccr}
\hline Trechos & Extensão & $\begin{array}{r}\text { Qtrecho }(\mathbf{L} / \mathbf{s}) \\
- \text { march }\end{array}$ \\
\hline 1 & 61,0 & 0,19 \\
2 & 104,5 & 0,32 \\
3 & 51,0 & 0,16 \\
4 & 104,5 & 0,32 \\
5 & 48,1 & 0,15 \\
6 & 48,1 & 0,15 \\
7 & 92,9 & 0,29 \\
8 & 5,3 & 0,02
\end{tabular}

Fonte: Autor.

Vazão por trecho

Considerando como nó seco a extremidade da rede e verificando cada trecho até chegar ao reservatório juntamente com a vazão em marcha, tem-se que a vazão no trecho1 e 2 é igual a zero, devido os pontos N7 e N8 serem nós secos. No trecho 3 considerou-sea soma das vazões em marchas do trecho 1 e 2, no qual a vazão foi definida, $\mathrm{Q}_{\text {jusante }}=0,19$. A vazão no trecho 4 foi obtida somando-se a vazão em marcha do trecho 3 com a vazão de jusante do trecho 3 , chegando-se ao resultado de 0,67 . Nos trechos 5 e 6 a vazão é igual a zero devido aos nós secos em N4 e N5. No trecho 7, somou-se a vazão do trecho 4 com as 
vazões em marcha dos trechos 5 e 6 , chegando-se ao valor de 1,291/s. Por fim no trecho 8encontrou-seos valores de vazão do reservatório, de 1,581/s. Os dados das vazões de jusante e em marcha estão dispostos na Tabela 4.

Tabela 4 - Tabela valores vazão e vazão em marcha por trecho

\begin{tabular}{cccc}
\hline Trechos & Extensão & $\begin{array}{c}\text { Qjusante } \\
(\mathbf{L} / \mathbf{s})\end{array}$ & $\begin{array}{c}\text { Qtrecho } \\
(\mathbf{L} / \mathbf{s})\end{array}$ \\
& & & marcha \\
\hline 1 & 61 & 0,00 & 0,19 \\
2 & 104,5 & 0,00 & 0,32 \\
3 & 51,02 & 0,51 & 0,16 \\
4 & 104,5 & 0,67 & 0,32 \\
5 & 48,1 & 0,00 & 0,15 \\
6 & 48,1 & 0,00 & 0,15 \\
7 & 92,91 & 1,29 & 0,29 \\
8 & 5,3 & 1,58 & 0,02
\end{tabular}

Fonte: Autor

\section{Velocidade e diâmetro da tubulação}

Os diâmetros das tubulações foram definidos coma relação dos valores obtidos das velocidades máximas em cada trecho e os valores limites das vazões fictícias por diâmetro, determinadas de acordo com a Tabela 5.

Tabela 5 - Diâmetro em função das velocidades e vazões máximas.

\begin{tabular}{ccc}
\hline $\mathbf{D}(\mathbf{m m})$ & $\mathbf{V m a x}(\mathbf{m} / \mathbf{s})$ & $\mathbf{Q m a x}(\mathbf{l} / \mathbf{s})$ \\
\hline 50 & 0,5 & 1 \\
75 & 0,5 & 2,2 \\
100 & 0,6 & 4,7 \\
\hline
\end{tabular}

\begin{tabular}{lll}
\hline 150 & 0,8 & 14,1 \\
200 & 0,9 & 28,3 \\
250 & 1,1 & 53,9 \\
300 & 1,2 & 84,8 \\
350 & 1,3 & 125 \\
400 & 1,4 & 176 \\
450 & 1,5 & 238 \\
500 & 1,6 & 314 \\
550 & 1,7 & 403 \\
600 & 1,8 & 509 \\
\hline
\end{tabular}

Fonte: Autor

No resultado da velocidade máxima foram considerados os valores da média aritmética dos valores de montante e jusante de cada trecho para foi calculado os valores das vazões fictícias. Foi encontrado valores diferentes para cada trecho, desta forma foram adotados para os tubos de PVC diâmetros de $50 \mathrm{~mm}$ e $75 \mathrm{~mm}$, conforme cada trecho analisado na tabela 6 .

Tabela 6 - Informações das vazões fictícias, diâmetros e velocidade por trecho.

\begin{tabular}{|c|c|c|c|c|c|c|}
\hline Trechos & $\begin{array}{c}\mathbf{Q j} \\
(\mathbf{L} / \mathbf{s})\end{array}$ & $\begin{array}{c}\text { Qtrecho } \\
(\mathrm{L} / \mathrm{s})- \\
\text { marcha }\end{array}$ & $\begin{array}{l}\text { Qm } \\
(\mathrm{L} / \mathbf{s})\end{array}$ & $\begin{array}{c}\text { Qf } \\
(\mathbf{L} / \mathbf{s})\end{array}$ & $\begin{array}{c}D \\
(\mathbf{m m})\end{array}$ & $\begin{array}{c}\mathbf{V} \\
(\mathrm{m} / \mathbf{s})\end{array}$ \\
\hline 1 & 0,00 & 0,19 & 0,19 & 0,09 & 50 & 0,05 \\
\hline 2 & 0,00 & 0,32 & 0,32 & 0,16 & 50 & 0,08 \\
\hline 3 & 0,51 & 0,16 & 0,67 & 0,59 & 50 & 0,30 \\
\hline 4 & 0,67 & 0,32 & 0,99 & 0,83 & 50 & 0,42 \\
\hline 5 & 0,00 & 0,15 & 0,15 & 0,07 & 50 & 0,04 \\
\hline 6 & 0,00 & 0,15 & 0,15 & 0,07 & 50 & 0,04 \\
\hline 7 & 1,29 & 0,29 & 1,58 & 1,43 & 75 & 0,32 \\
\hline 8 & 1,58 & 0,02 & 1,60 & 1,59 & 75 & 0,36 \\
\hline
\end{tabular}

\section{Pressões}


Para determinar os valores das pressões, foram levados em consideração os valores das perdas de carga em cada trecho, que correspondem à perda unitária multiplicada pelo comprimento do trecho, ainda considerando que serão utilizados tubos de PVC, que possuem uma rugosidade de $\mathrm{C}=140$. De posse dos valores das perdas de carga foi possível encontrar as cotas piezométricas de montante e jusante. A partir destas cotas e as cotas do terreno, foram encontrados como resultados os valores das pressões em cada nó conforme Tabela 7. A pressão estática máxima desta rede ficou definida como 21 m.c.a. 
Tabela 7 - Tabela das pressões, perdas de cargas e cotas por trecho

\begin{tabular}{|c|c|c|c|c|c|c|c|c|c|}
\hline \multicolumn{2}{|c|}{ Perda de carga } & \multicolumn{2}{|c|}{ Cota $(\mathrm{m})$} & \multicolumn{2}{|c|}{$\begin{array}{l}\text { Cota Piezométrica } \\
\qquad(\mathrm{m})\end{array}$} & \multirow{2}{*}{\multicolumn{2}{|c|}{$\begin{array}{c}\text { Pressão } \\
\text { (mca) }\end{array}$}} & \multirow[b]{2}{*}{ Trechos } & \multirow[b]{2}{*}{ Extensão } \\
\hline $\begin{array}{c}\text { Unitária } \\
\text { (m) }\end{array}$ & $\begin{array}{l}\text { trecho } \\
\text { (mca) }\end{array}$ & Montante & Jusante & Montante & Jusante & & & & \\
\hline 0,0001 & 0,01 & 401,00 & 402,00 & 412,69 & 412,68 & 11,69 & 10,68 & 1 & 61 \\
\hline 0,0002 & 0,02 & 401,00 & 392,00 & 412,69 & 412,66 & 11,69 & 20,66 & 2 & 104,5 \\
\hline 0,0026 & 0,13 & 399,00 & 401,00 & 412,82 & 412,69 & 13,82 & 11,69 & 3 & 51,02 \\
\hline 0,0048 & 0,51 & 399,00 & 394,00 & 412,82 & 412,31 & 13,82 & 18,31 & 4 & 104,5 \\
\hline 0,0001 & 0,00 & 394,00 & 394,00 & 412,31 & 412,31 & 18,31 & 18,31 & 5 & 48,1 \\
\hline 0,0001 & 0,00 & 399,00 & 397,00 & 412,82 & 412,81 & 13,82 & 15,81 & 6 & 48,1 \\
\hline 0,0018 & 0,17 & 402,00 & 399,00 & 412,99 & 412,82 & 10,99 & 13,82 & 7 & 92,91 \\
\hline 0,0022 & 0,01 & 401,00 & 402,00 & 413,00 & 412,99 & 12,00 & 10,99 & 8 & 5,3 \\
\hline
\end{tabular}

Fonte: Autor 


\section{Altura Reservatório}

Após a realização dos cálculos para o dimensionamento e analisar as pressões, foi verificado que a cota piezométrica do reservatório é igual a $413 \mathrm{~m}$ e a conta a jusante do terreno no trecho dois é igual a 392m. Então o reservatório elevado deve possuir 12 metros de altura em relação ao nível do solo.

\section{Conjunto motor bomba}

Com a rede de distribuição dimensionada temos a altura do reservatório definido em $12 \mathrm{~m}$, agora pode-se calcular a bomba de recalque que alimentará o reservatório.

Com a população definida da área de estudo deste trabalho em 380 habitantes e que a vazão necessária para abastecer a população considerando o consumo diário per capta em 2001/hab.dia, portanto serão necessários 76.000 litros de água por dia para atender a demanda da população, ou seja, um volume (V) de $76 \mathrm{~m}^{3}$.

Por uma questão de estratégia econômica, considerou-se que o sistema funcionasse 8 horas por dia. $\mathrm{O}$ cálculo da vazão foi realizado através da equação 8 , com pode ser visualizado abaixo.

$$
Q=\frac{76 \mathrm{~m}^{3}}{8 h}=9.5 \frac{\mathrm{m}^{3}}{h}=0,002638 \mathrm{~m}^{3} / \mathrm{s}
$$

Com a vazão de recalque determinada, foi calculado o diâmetro de recalque através da equação 10 , como segue descriminado a seguir.

$D r=1,3 \cdot \sqrt[4]{\frac{8}{24}} \cdot \sqrt[2]{0,002638}=0,0507 m=$ $50 \mathrm{~mm}$

Foi calculado em seguida a velocidade econômica conforme Equação 11 para comprovar que o diâmetro escolhido atende a norma.

$$
v=\frac{4 \times 0,002638}{\pi \times 0,0507^{2}}=1,306 \mathrm{~m} / \mathrm{s}
$$

Com o valor da velocidade econômica atendida para o cálculo do diâmetro de recalque, fica determinado que os diâmetros da tubulação de recalque e sucção são iguais a $50 \mathrm{~mm}$ e $75 \mathrm{~mm}$ respectivamente.

Para determinar a potência do conjunto motor bomba, calculou-se a perda de carga ao longo da tubulação de recalque

$$
\begin{gathered}
\mathrm{J}=10,643 \frac{Q^{1,85}}{C^{1,85} D^{4,87}} L=10,643 \cdot \frac{0,002638^{1,85}}{140^{1,85} 0,05^{4,87}} \cdot 12 \\
=0,503 \mathrm{~m}
\end{gathered}
$$

pela Equação 2.

Com a perda de carga no trecho encontrada, calculou-se a altura manométrica pela Equação 9.

$$
H_{m}=10+0,418 \rightarrow H_{m}=12,503 \mathrm{~m}
$$


Consultando o Ábaco de cobertura da KSB (Anexo1) com os dados encontrados de altura manométrica, igual a $12,503 \mathrm{~m}$, e uma vazão de $9,5 \mathrm{~m}^{3} / \mathrm{h}$, chega-se a seleção da bomba modelo 32-160.1, de 1.750 RPM.

De acordo com o ábaco foi escolhido o modelo 32-160.1 do fabricante KSB da linha KSB Megachem e através do catalogo do modelo da bomba (Anexo 2) identifica-se utilizando o valor da vazão e altura manométrica o valor do rendimento de $44 \%$ e o valor do diâmetro do impelidor de $169 \mathrm{~mm}$.

Com o valor obtido do diâmetro do impelidor de 169 mm e a vazão é possível através do o cruzamento de informações no Ábaco de escolha da potência da bomba (Anexo 3), onde foi encontrado o valor de potência $\mathrm{P}=0,96 \mathrm{HP}$ ou $\mathrm{P}=0,97 \mathrm{CV}$.

Utilizando o valor de rendimento de 44\% encontrado no ábaco da KSB (Anexo 3) na Equação 7, foi calculado o valor da potência do conjunto motor bomba.

$\mathrm{P}=\frac{1000 \cdot 0,002638 \cdot 10,418}{75 \cdot 0,44}=0,999 \mathrm{CV}$

Encontrado a potência do conjunto motor bomba tanto pelo ábaco da KSB

\section{CONCLUSÕES}

Foi verificado a necessidade de um sistema de abastecimento para atender um
(Anexo 3) como pela equação 7 , foi definido uma bomba comercial de $1,5 \mathrm{CV}$ para ser utilizado na estação elevatória.

Planta localização projeto com tubulação e reservatório

Após todo o dimensionamento efetuado é possível apresentar a planta com as curvas de nível do loteamento e o traçado da rede de abastecimento, em apenas uma parte do referido empreendimento, atendendo a demanda atual do mesmo, onde serão beneficiados moradores daquela área.

Procurou-se aproveitar ao máximo, a declividade do terreno, para garantir a todos os pontos de consumo a pressão adequada sugerida pela norma.

Figura 13 - Planta de localização do loteamento com trajeto da tubulação

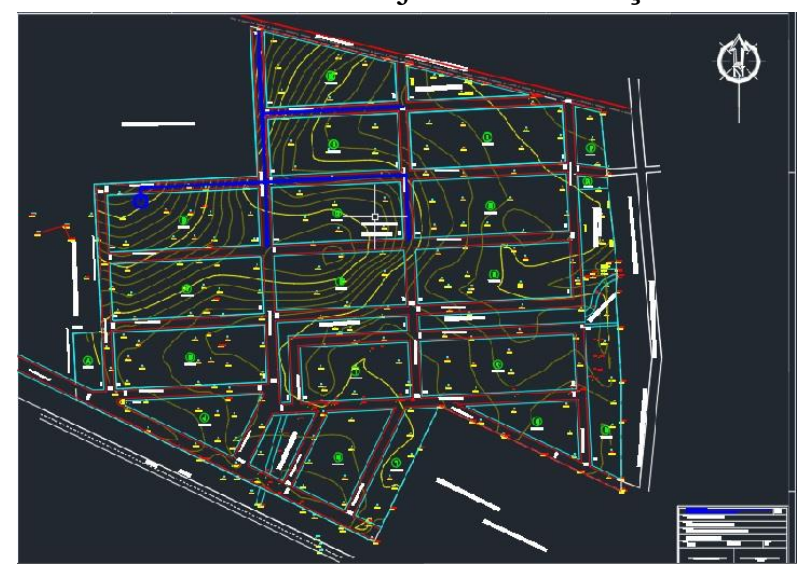

Fonte: Autor

trecho do loteamento onde existem unidades comercializadas com uma demanda para ser atendida. 
Atualmente o município é atendido com um sistema de rodízio no abastecimento de água em função do reservatório principal, que fornece a água, encontrar-se com uma capacidade reduzida, porém garantindo o abastecimento, de forma a ter um bom funcionamento de um SSA.

O dimensionamento de um sistema de abastecimento para um trecho do loteamento foi considerado satisfatório e irá atender a demanda da população residente nas unidades comercializadas

\section{REFERÊNCIAS}

ANA - Agencia Nacional de Águas.

Conjuntura Apresenta: Uso da água.

2019. Disponível em:

<http://conjuntura.ana.gov.br/usoagua >. Acesso em:19 de maio de 2020.

APAC - Agência Pernambucana de Águas e Clima. Boletim do Monitoramento dos reservatórios. 2020. Disponível em: <http://www.apac.pe.gov.br/arquivos_ portal/boletinsreservatorios/Boletim_Monit oramento_Reservatorios_05_06_2020.pdf >. Acesso em: 7 de junhode 2020. APAC - Agência Pernambucana de Águas e Clima. Monitoramento Hidrológico. 2020. Disponível em: <http://www.apac.pe.gov.br/monitorament o/>. Acesso em: 7 de junho de 2020.

ARAÚJO, F. M. Algumas Características de Uma Estação Elevatória de Água.

Trabalho de conclusão de curso (Graduação em Física - Universidade Estadual da Paraíba), Campina Grande PB, 2014. Disponível
Os resultados encontrados podem ser utilizados pela concessionária local para o estudo de viabilidade técnica.

Como proposta para trabalhos futuros poderiam ser utilizadas a captação das águas pluviais e o uso de águas cinzas, como fontes de abastecimento e seus usos específicos, tem assim alternativas na ausência da forma tradicional de abastecimento utilizada pela concessionária.

em:<http://dspace.bc.uepb.edu.br/jspui/bits tream/123456789/8291/1/PDF\%20-

\%20Francid\%C3\%A9zio\%20Meira\%20de $\% 20$ Ara\%C3\%BAjo.pdf $>$. Acesso em: 25 de maio de 2020.

BRASIL. Lei ${ }^{\circ}$ 9.433, de 8 de janeiro de 1997. Política Nacional de Recursos

Hídricos. Brasília: Secretaria de Recursos Hídricos. 1997. Disponível em: $<$ http://www.planalto.gov.br/ccivil_03/LEI S/L9433.htm>. Acesso em: 28 de abril de 2020.

BRASIL. Ministério do Meio Ambiente. Plano Nacional de Saneamento Básico. 2020. Disponível em: <https://www.mma.gov.br/informma/item/ 485-plano-nacional-de-saneamentob\%C3\%A1sico.html>. Acesso em: 28 de abril de 2020.

COMPESA - Companhia Pernambucana de Saneamento. Barragem de Jucazinho volta a acumular água. 2018. Disponível em:

$<$ https://servicos.compesa.com.br/barrage 
m-de-jucazinho-volta-a-acumular-agua/> . Acesso em: 7 de junho de 2020.

FILHO, C. F. M. ' Abastecimento de Água'. UFCG, Campina Grande.

Disponível em:

$<$ http://www.margarita.dea.unir.br/uploads /11523232/arquivos/Apostilha_Abast_de_ Agua_UFCG_1632633735.pdf>. Acesso em: 12 de junho de 2020

FUNASA. FUNDACÃO NACIONAL DE SAÚDE. Manual do Saneamento.

Brasília, DF, 2015.

GUIMARÃES, A. J. A.; CARVALHO, D. F.; SILVA, L. D. B.Saneamento Básico. 2007. 9 f. Tese (Doutorado) - Curso de Engenharia Sanitária, Universidade Federal da Paraíba, João Pessoa, 2007. Cap. 1. Disponível em: http://www.ufrrj.br/institutos/it/deng/leona rdo/downloads/APOSTILA/Apostila\%20I T\%2017 9/Cap\%201.pdf. Acesso em: 22 de maio de 2020.

HELLER, L.; PÁDUA, V.L.

Abastecimento de água para consumo humano. $2^{\mathrm{a}}$ ed. Belo Horizonte: Editora UFMG, 2010. V. 1 e 2. Instituto Trata Brasil. Manual de Saneamento Básico.2012. Disponível em:<http://www.tratabrasil.org.br/datafiles /uploads/estudos/pesquisa16/manualimprensa.pdf $>$. Acesso em: 28 de abril de 2020.

Instituto Trata Brasil. O que é

Saneamento? 2020. Disponível em:<http://www.tratabrasil.org.br/saneame nto/o-que-e-saneamento $>$. Acesso em 20 de maio 2020.

Instituto Trata Brasil. Venha Conhecer as Etapas para o Tratamento de Água.

2019. Disponível em:

$<$ http://www.tratabrasil.org.br/blog/2019/0

4/18/venha-conhecer-as-etapas-para-otratamento-de-agua/>. Acesso em: $25 \mathrm{de}$ maio de 2020.
KBS Bombas Hidráulicas. Manual de Curvas Características das Bombas

KSB. VárzeaPaulista, SP, 2013.

MITCHELL, V.G. Applying Integrated Urban Water Management Concepts: A Review of Australian Experience. Environmental Management, 2007. SNIS - Sistema Nacional de Informações Sobre Saneamento. Componentes do SNIS. Disponível em: <http://www.snis.gov.br/componentes/men u-snis-componente-agua-eesgotos>.Acesso em: 25 de Maio de 2020 SNIS - Sistema Nacional de Informações Sobre Saneamento. Diagnóstico dos Serviços de água e Esgoto - 2018.

Disponível em:

$<$ http://www.snis.gov.br/diagnosticoanual-agua-e-esgotos/diagnostico-dosservicos-de-agua-e-esgotos-2018>. Acesso em: 25de maiode 2020.

SOUZA, P. H. A. I. Apresentação dos cálculos para seleção de bomba para sistema de aproveitamento de água de poços artesianos. Projeto de Graduação (Graduação em Engenharia Mecânica Universidade Federal do Rio de Janeiro, Escola Politécnica), Rio de Janeiro, 2014.

Disponível em: $<$ http://monografias.poli.ufrj.br/monografi as/monopoli10012492.pdf >. Acesso em: 9 de junho de 2020.

TSUTIYA M.T. Abastecimento de água Departamento de engenharia hidráulica e sanitária da Escola Politécnica da Universidade de São Paulo, $4^{\circ}$ edição, p.4 - 9, 2006.

VOW SPERLIN, M. Princípios do Tratamento Biológico de Águas Residuárias: Introdução a Qualidade das Águas e ao Tratamento de Esgoto. V1, 4 ed. Belo Horizonte: EDUFMG, 2014. 
APAC - Agência Pernambucana de águas e Clima. Disponível em: <http://www.apac.pe.gov.br/meteorologia/ monitoramento-pluvio.php>. Acesso em: 07 de jun. 2020.

COPASA. Tratamento de água. Disponível em:

<http://www.copasa.com.br/wps/portal/int ernet/pesquisa-escolar/assuntos-maisacessados/tratamento-de-agua $>$. Acesso em: 11 de jul. 2020.

IBGE - Instituto Brasileiro de Geografia e Estatística. Disponível em:

<https://cidades.ibge.gov.br/brasil/pe/verte ntes/panorama>. Acesso em: 26 de mai. 2020.

ESQUADRÃO DO CONHECIMENTO. Estação de Tratamento de Água (ETA) Etapas. Disponível em:

$<$ https://esquadraodoconhecimento.wordpr ess.com/ciencias-da-

natureza/quim/estacao-de-tratamento-deagua-eta-etapas/>. Acesso em: 25 de mai. 2020.

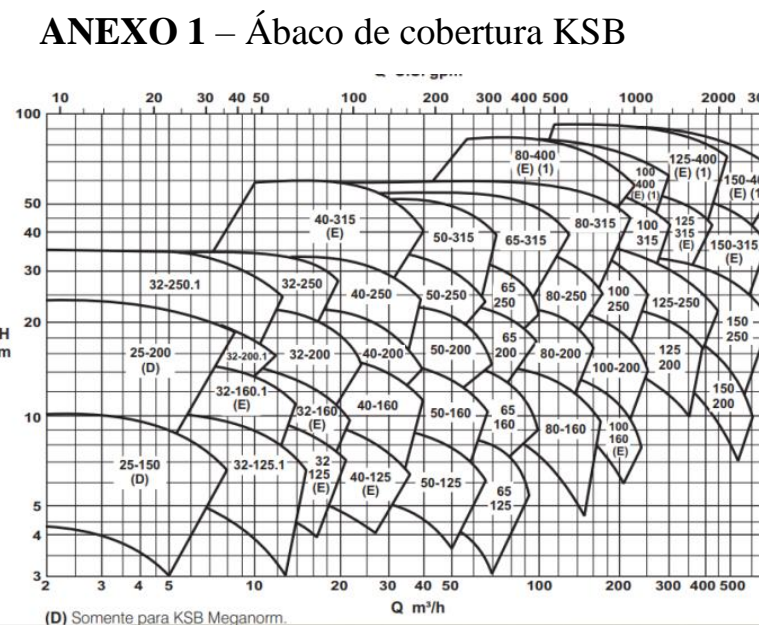

Fonte: KSB.

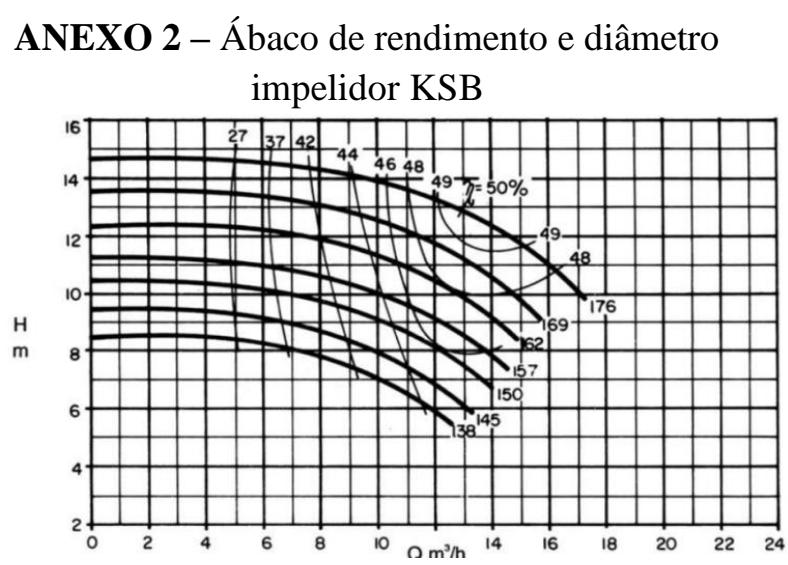

Fonte: KSB

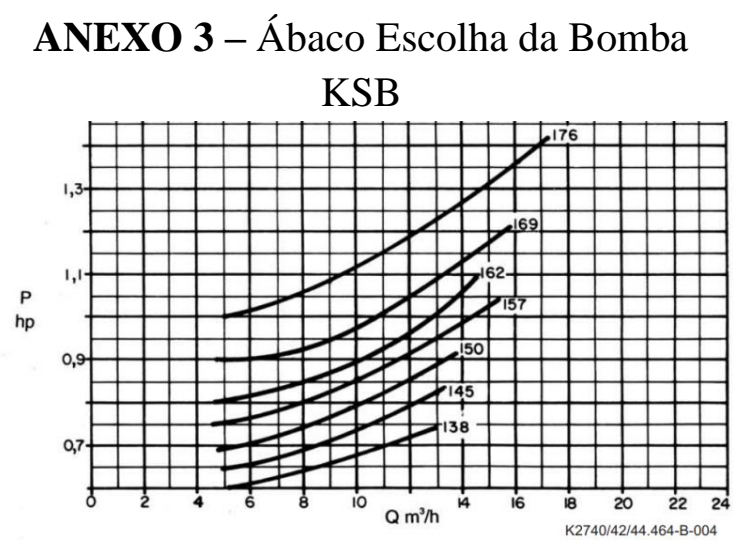

Fonte: KSB 
ANEXO 4 - Monitoramento Pluviométrico (mm) em Vertentes-PE

\begin{tabular}{|c|c|c|c|c|c|c|c|c|c|c|c|c|c|c|}
\hline Código & Posto & Ano & Janeiro & Fevereiro & Março & Abril & Maio & Junho & Julho & Agosto & Setembro & Outubro & Novembro & Dezembro \\
\hline 262 & Vertentes (IPA) & 2001 & - & - & - & - & - & - & - & - & - & - & 3,6 & - \\
\hline 262 & Vertentes (IPA) & 2009 & 19,9 & 157,6 & 55,2 & 85,6 & 82 & 46 & 67,2 & 84,5 & 7,1 & - & 15,7 & 26 \\
\hline 262 & Vertentes (IPA) & 2010 & 102,4 & 16,9 & 10,2 & 136,5 & 15,5 & 325,5 & 31,4 & 41,4 & 13,2 & 49,5 & - & 27,3 \\
\hline 262 & Vertentes (IPA) & 2011 & 88,8 & 3,5 & 78,7 & 92,3 & 234,2 & 95,7 & 132,9 & 75,7 & - & 18 & 18 & - \\
\hline 262 & Vertentes (IPA) & 2012 & 92,5 & 37,2 & - & 1 & 19,3 & 70,3 & 36,1 & 10,4 & - & 3,4 & - & 10 \\
\hline 262 & Vertentes (IPA) & 2013 & 7,9 & 1 & 6,5 & 66,8 & 28 & 73,2 & 97,7 & 56,6 & 1,7 & 14,3 & 23,1 & 22 \\
\hline 262 & Vertentes (IPA) & 2014 & 0,8 & 41,8 & 45,4 & 24,9 & 181,6 & 25,2 & 47,7 & 22,9 & 36,4 & 45,5 & 13,2 & 2,6 \\
\hline 262 & Vertentes (IPA) & 2015 & 2,2 & 8,6 & 20,6 & 12,5 & 32,7 & 99,6 & 101,7 & 12,9 & 2,5 & 4,2 & 2,7 & 60,8 \\
\hline 262 & Vertentes (IPA) & 2016 & 94,9 & 9,5 & 69,2 & 49,9 & 53,7 & 24,6 & 16,1 & 5,4 & 7,8 & - & - & 2,4 \\
\hline 262 & Vertentes (IPA) & 2017 & 1 & - & 16,4 & 58,7 & 66,9 & 63 & 84,8 & 16,1 & 26,6 & 3,5 & - & 7,3 \\
\hline 262 & Vertentes (IPA) & 2018 & 21,9 & 58,8 & 56,2 & 153,2 & 70,9 & 11,3 & 21,7 & - & - & - & 3,5 & 10,5 \\
\hline 262 & Vertentes (IPA) & 2019 & 20,5 & 38,8 & 38,8 & 63,9 & 20,8 & 86,8 & 75,4 & 69,5 & 9,9 & - & - & - \\
\hline 262 & Vertentes (IPA) & 2020 & 28,2 & 61,5 & 87,8 & 86,9 & 49,5 & - & - & - & - & - & - & - \\
\hline
\end{tabular}

Fonte: APAC 